\title{
EINFLUSS DER DEUTSCHEN RECHTSTERMINOLOGIE AUF DIE KROATISCHE RECHTSSPRACHE AM BEISPIEL DES STRAFPROZESSRECHTS
}

Prof. dr. sc. Ljubica Kordic**

\author{
UDK 34:82.03 \\ 811.163.42:34.01 \\ https://doi.org/10.30925/zpfsr.42.3.5 \\ Ur.: 27. travnja 2021. \\ Pr.: 15. lipnja 2021. \\ Prethodno priopćenje
}

\section{Zusammenfassung}

Obwohl die deutsche und die kroatische Rechtssprache auf verschiedenen Kulturen und Rechtssystemen beruhen, und die Wortbildungssysteme der deutschen und der kroatischen Sprache sich im großen Maße unterscheiden, sind die Einflüsse der deutschen Rechtsterminologie auf die kroatische Rechtssprache wegen der rechtshistorischen Verankerung des kroatischen Rechtssystems im österreichischen Recht auch heute erkennbar. Wie intensiv diese Einflüsse sind, erkennt man am besten an Übersetzungen kulturell gefärbter Ausdrücke metaphorischen und rhetorischen Charakters, denn diese Ausdrücke sollten für jede Kultur und jede Sprache eigentümlich sein. Um die Hypothese nachzuweisen, dass die kroatische Rechtssprache von der deutschen Sprache des Rechts intensiv beeinflusst wurde, bedient sich die Autorin der Methode der qualitativen Textanalyse, der quantitativen und der vergleichenden Methode, und analysiert die Beispiele von kulturell nuancierten metaphorischen Ausdrücken, Kollokationen und Phrasen in der deutschen und der kroatischen Rechtssprache im Bereich des Strafprozessrechts. Als Korpus der Untersuchung dienen die im Internet erreichbaren Texte der deutschen StPO vom 15.11.2019, Stand: 01.09.2020 (BGBl. IS. 1604) und des kroatischen Gesetzes zu Änderungen der StPO der Republik Kroatien vom 17.12.2019.

Schlüsselwörter: deutsche Rechtssprache; kroatische Rechtssprache; Einfluss; metaphorische Ausdrücke; rechtshistorische Verbindungen.

* Ljubica Kordić, dr. sc. außerordentliche Professorin, Fakultät für Rechtswissenschaften der Josip-Juraj-Strossmayer-Universität in Osijek; kljubica@pravos.hr. ORCID: https://orcid. org/0000-0002-2900-7906.

Dieses Papier ist ein Produkt von Arbeiten, die vollständig durch das Jean Monnet Module Language and EU Law Excellence LEULEX, Projekt No 620231-EPP-1-2020-1-HR-EPPJMOMODULE. unterstützt wurden.

Die Unterstützung der Europäischen Kommission für die Erstellung dieser Veröffentlichung stellt keine Billigung des Inhalts dar, welcher nur die Ansichten der Verfasser wiedergibt, und die Kommission kann nicht für eine etwaige Verwendung der darin enthaltenen Informationen haftbar gemacht werden. 


\section{EINLEITUNG}

Seit 70er Jahren des 20. Jh. wird in der Übersetzungslehre der funktionalistische Ansatz angewandt. Nach diesem Ansatz werden kulturelle Unterschiede zwischen der Ausgangs- und der Zielsprache und die Funktion des Zieltextes als wichtigste Grundsätze der Übersetzung betrachtet. Dies betrifft insbesondere die Phrasen metaphorischen Charakters, Syntagmen mit Funktionsverben und metaphorische Kollokationen im Bereich der Rechtssprache, die kulturspezifisch und als solche kaum übersetzbar sind. Der Einfluss der jeweiligen Kultur auf diese Strukturen lässt sich leicht durch einen Vergleich von deutschen und kroatischen Sprichwörtern nachweisen, die immer eine übertragene Bedeutung aufweisen. Es ist allgemein bekannt, dass der Einfluss der deutschen Kultur auf die kroatische wegen der rechtshistorischen Verbindungen und der systematischen Ansiedlungen von Deutschen und Österreichern in kroatische Gegenden von 17. bis zum 20. Jh. beträchtlich war. ${ }^{1}$ Dass metaphorische Ausdrücke, Redewendungen und Sprichwörter kulturspezifisch sind, erkennt man an alltäglichen Kollokationen, die in der kroatischen Sprache mit anderen sprachlichen Mitteln und einer abweichenden Metaphorik als im Deutschen ausgedrückt sind oder überhaupt nicht metaphorisch sind, wie z.B, Rotwein versus crno vino (schwarzes Wein), Schwarzmarkt versus sivo tržište (grauer Markt), Klavier spielen versus biti uhićen (verhaftet werden), usw. Als Beweis dafür dient auch der Vergleich von deutschen Sprichwörtern, die Buscha in seinem Übungsbuch für Germanistikstudenten gesammelt hat, ${ }^{2}$ mit ihren kroatischen Entsprechungen. Die Analyse von 98 Beispielen und ihrer kroatischen Entsprechungen zeigt, dass nur 28,5\% der deutschen Sprichwörter in demselben metaphorischen Kontext in der kroatischen Kultur gebräuchlich sind (27 von 98 Sprichwörtern), während 71,5\% in der kroatischen Kultur überhaupt nicht bekannt sind. Die Sprichwörter wie mit einer Klappe zwei Fliegen schlagen, wie Hund und Katze zusammenleben, etwas zum alten Eisen werfen, jemandem den Korb geben, mit dem Kopf durch die Wand wollen, den Kopf in den Sand stecken, und manche andere bestehen in derselben semantischen und lexikalischen Form in der kroatischen Sprache. Die Sprichwörter, deren metaphorische Inhalte in der kroatischen Sprache mit anderen lexikalischen Mitteln oder mit einer anderen Metaphorik als in der deutschen Sprache ausgedrückt sind, können mit folgenden Beispielen illustriert werden: jemandem raucht aus dem Kopf (Kroatisch: puši mu se iz ušiju), nach jemands Pfeife tanzen (Kroatisch: plesati kako drugi svira), ein Haar in der Suppe finden (Kroatisch: tražiti dlaku u jajetu), seinen Mantel nach dem Winde hängen (Kroatisch: okretati se kako vjetar puše). Andere deutsche Sprichwörter sind der kroatischen Kultur unbekannt (z. B. auf den Hund kommen, sein Schäfchen ins Trockne bringen, wie die Herringe stehen, auf den Busch klopfen, mit jemandem Schlitten fahren, jemanden in die Zange nehmen, usw.). Diese kurze Analyse bestätigt die Auffassung, dass metaphorische Ausdrücke kulturspezifisch und oft kaum übersetzbar sind, obwohl der Einfluss der deutschen

1 Die Quellen dazu: Josip Bösendorfer, Crtice iz slavonske povijesti (Osijek, Knjigo- i kamenotiskara Julija Feiffera 1910.); Ive Mažuran et al., Od turskog do suvremenog Osijeka (Zagreb: Školska knjiga d.d., 1996.)

2 Joachim Buscha, Deutsches Übungsbuch. (Leipzig: VEB Verlag Enzyklopädie, 1979) 
und der österreichischen Kultur auf die kroatische in vielen Lebensbereichen unbestritten ist. Die Hypothese dieser Arbeit ist es, dass der Einfluss der deutschen Rechtsterminologie auf die kroatische auch im Bereich der metaphorischen Ausdrücke intensiver ist als in der Allgemeinsprache.

Das kroatische Rechtssystem ist historisch im Rechtssystem des österreichischen Kaisertums, später des Österreich-Ungarischen Kaisertums tief verankert. Folglich ist auch die kroatische Rechtssprache mit der deutschen Rechtssprache verbunden. Dies wurde in früheren Arbeiten von kroatischen Linguisten aus unterschiedlichen Perspektiven untersucht. ${ }^{3}$ Im Jahre 1850, als das viersprachige Wörterbuch „Juridisch-politische Terminologie für die slawische Sprachen Österreichs” in Wien veröffentlicht wurde, wurden juristische Termini und Phrasen aus dem Deutschen ins Kroatische übersetzt. Viele neue Rechtstermini wurden in Einklang mit den puristischen Bestrebungen gebildet, die damals zur Zeit der Nationalbewegungen in Europa sehr geprägt waren. Eine Anzahl der Fachtermini wurde auch von der deutschen Sprache ins Kroatische wortwörtlich übersetzt. ${ }^{4}$ Die Aufgabe dieser Arbeit ist es, zu überprüfen, ob und in welchem Maße metaphorische Ausdrücke im Bereich der deutschen und der kroatischen Rechtssprache übereinstimmen, und ob in kroatischen Äquivalenten der ursprüngliche metaphorische Charakter des deutschen Ausdrucks erhalten geblieben ist. Da metaphorische Ausdrücke kulturbedingt sind (was am Beispiel deutscher Sprichwörter veranschaulicht wurde), wird die Analyse der aus dem Korpus exzerpierten Beispiele der deutschen Rechtsausdrücke metaphorischen Charakters und ihrer kroatischen Äquivalenten zeigen, wie intensiv die deutsche Rechtsterminologie und -phraseologie die kroatische Rechtssprache beeinflusst hat.

\section{GEGENSTAND UND ZIEL DER UNTERSUCHUNG}

Metapher ist auch heute eines der stilistischen Merkmale der Rechtssprache. Unter dem Terminus Metapher ist die stilistische Figur verstanden, mit der eine Sache oder ein Phänomen durch eine andere Sache oder Phänomen ersetzt wird, mit dem Ziel, Aufmerksamkeit zu erregen (,... a stylistic figure denoting a thing or item different from that which it originally was attached to, its purpose being to draw attention to a perceived resemblance." $)^{5}$ Nach Lakoff und Johnson ist Metapher das grundlegende

3 Dragica Bukovčan, „Wer sitzt hinter schwedischen Gardinen und wer spielt Klavier? Fachphraseologie und ihre kulturelle Relevanz", Jezikoslovlje, 16.1 (2015), 1-20; Dragica Bukovčan, „Integralni pristup frazeološkim i metaforičkim izrazima u području prava“ in: Lingvistički i pravni aspekti višejezičnosti, ur. Lelija Sočanac (Zagreb: Nakladni zavod Globus, 2013), 243-276; Ljubica Kordić, „Metafora u njemačkom i hrvatskom pravnom idiomu“, Lingua Montenegrina, 6 (2010), 229-240; Ljubica Kordić, „Metaphoric Use of Colour Denotations in the Language of Law", Studies in Logic, Grammar and Rhetoric, 58/1 (2019),101-124; Mile Mamić, Temelji hrvatskoga pravnog nazivlja (Zagreb: Hrvatska sveučilišna naklada, 1992.); Snježana Husinec, „Metafora u pravnom diskursu“, in: Diskurs i dijalog: Teorije, metode $i$ primjena, ur. Vladimir Karabalić, Melita Aleksa Varga und Leonard Pon (Osijek: Hrvatsko društvo za primijenjenu lingvistiku; Filozofski fakultet, 2011), 69-84.

4 Mamić, Temelji hrvatskoga pravnog nazivlja, 1992, 7.

5 Milica Mihaljević und Ljiljana Šarić, „Metaforizacija kao terminološki postupak u engleskom i hrvatskom“, Suvremena lingvistika, 41/42 (1996): 437 
Mittel zum Verstehen der Welt, in der wir leben und ,a basic process pervading all our speaking, thinking and acting."

Der metaphorische Charakter der Rechtssprache ist schon jahrhundertelang als ein der Merkmale dieser Fachsprache erkennbar. Ein der ersten Linguisten (und Juristen), die sich mit poetischen Figuren in der Rechtssprache befasst haben, war Jakob Grimm, der eine wissenschaftliche Erörterung unter dem Namen „Von der Poesie im Recht" in der Zeitschrift für geschichtliche Rechtwissenschaft vor mehr als 200 Jahren (1816) veröffentlicht hat. ${ }^{7}$ Den Forschungen von Grimm verdanken wir Erkenntnisse über den metaphorischen Charakter der ältesten Rechtregel des germanischen Rechts. In seiner Arbeit illustriert Grimm mit vielen Beispielen, dass die altgermanischen Regelungen in der Form von metaphorischen Versen, Sprüchen und Wendungen ausgedrückt wurden. Da die Rechtsregeln damals mündlich überliefert wurden, wurden sie mit Hilfe von metaphorischen Bildern, Symbolik, und oft in der Form von Versen ausgedrückt, um leichter memoriert zu werden. So waren beispielsweise die Rechtsinstitute wie Mobilien und Immobilien, Begrenztheit und Unbegrenztheit des Eigentums folgenderweise formuliert:

Mobilien: was der Wind beweht und die Sonne bescheint;

Immobilien: was die Egge bestrichen und die Hecke bedeckt hat

Eigentum: Soweit der blaue Himmel langt,

aber auch: Soweit der Hahn schreitet, soweit die Katze springt, soweit der Hammer geworfen wird.

Das Eigentum einer verheirateten Frau: Eine Frau hat während der Ehe den blauen Himmel und den Spinnrocken

Corpus delicti: Wo sich der Esel wälzt, da muss er Haare lassen.

Die Strafe für Diebstahl: Mäuse soll man fangen - Diebe soll man hangen.

Mattila analysiert dieses Phänomen in seiner umfangreichen rechtslinguistischen Studie Comparative Legal Linguistics: „Ancient laws of Germanic tribes (...) were expressed through magical formulas, whose melodious character affirmed in listeners a depth of feeling that ensured respect for legal rules."

Auch im heutigen deutschen Recht bestehen viele polylexikalische Ausdrücke metaphorischen Charakters in allen Rechtsgebieten: zur Last legen, zur Last liegen, in Kraft treten, Verfassung verabschieden, Klage erheben, Berufung einlegen, usw. Im Fokus der Untersuchung in dieser Arbeit sind metaphorische Ausdrücke, Phrasen und Kollokationen im Bereich des Strafprozessrechts.

Warum sind gerade metaphorische Ausdrücke der Gegenstand dieser Forschung? Wie in der Einleitung angedeutet, wurde in den 80er Jahren des 20. Jahrhunderts die Kultur der Ausgangs- und der Zielsprache zum ersten Mal als ein wichtiger Faktor der Übersetzung hervorgehoben. Dieser funktionalistische Ansatz zur Übersetzung, entwickelt von Hans Vermeer und Katharina Reiß, wurde auch die Skopos-Theorie genannt (griechisch skopos $=$ Zweck). Für diese Arbeit ist folgende Behauptung von

6 George Lakoff und Mark Johnson. Metaphors we live by. Chicago: University of Chicago Press, 1980

7 Diese Daten verdanke ich Günther (Lothar Günther, Sprache und Recht. Wien: 1898).

8 Heikke Mattila, Comparative Legal Linguistics. Hampshire: Ashgate, 2006. 
Reiß und Vermeer von besonderer Bedeutung: „Übersetzen von Rechtstexten ist eine Sondersorte des kulturellen Transfers." Das Ziel dieser Arbeit ist es, durch die Analyse von Beispielen der kulturell nuancierten metaphorischen Ausdrücke aus dem Bereich des Strafprozessrechts und ihrer kroatischen Entsprechungen zu beweisen, dass die Einflüsse der deutschen Rechtsterminologie auf die kroatische Rechtssprache - in diesem Fall die Sprache des Strafprozessrechts - trotz kulturellen Unterschieden intensiv präsent und stärker als in der Allgemeinsprache geprägt sind.

\section{KORPUS UND METHODE DER UNTERSUCHUNG}

Die Untersuchung gründet sich auf zwei Korpora. Den ersten bildet der Text der deutschen Strafprozessordnung - StPO vom Jahr 2019 (Stand: 09.10.2020. BGB1. I S. 1604), ${ }^{10}$ und den zweiten das Gesetz zu Änderungen der StPO der Republik Kroatien vom 17.12.2019. ${ }^{11}$ Der Hauptteil der Belege ist dem Text der deutschen StPO entnommen, während die Belege, die im kroatischen Korpus aufgefunden sind, zur Bestätigung der Befunde der Analyse von Belegen im deutschen Korpus und ihrer kroatischen Entsprechungen dienen. Der Text der deutschen StPO von 2019, Stand: 9.10.2020 (BGBl. I S. 1604) umfasst 163 Artikeln auf 189 Seiten. Der Untersuchung stützt sich auf 90 Artikeln auf 98 Seiten. Die angewandten Methoden sind die Methode der manuellen Exzerption der Belege, die Methode der qualitativen Textanalyse, die quantitative Methode und die vergleichende Methode. Die Termini und polylexikalische Ausdrücke werden durch ausführliches Lesen des Textes exzerpiert, gesammelt und systematisiert. Danach werden sie einer semantischen Analyse unterzogen und gegen ihre kroatischen Entsprechungen verglichen. Quantitative Daten über semantische und lexikalische Überlappungen der metaphorischen Ausdrücke der deutschen Rechtssprache und ihrer kroatischen Entsprechungen werden auch mit den Daten über semantische und lexikalische Überlappungen zwischen den deutschen und kroatischen Sprichwörtern aus der Alltagssprache verglichen. Danach werden metaphorische Ausdrücke aus dem Gesetz zu Änderungen der Strafprozessordnung der Republik Kroatien mit Verwendung derselben Methode exzerpiert und analysiert. Am Ende werden die Ergebnisse der vergleichenden Analyse systematisiert und Schlussfolgerungen gezogen.

9 Katarina Reiss und Hans Vermeer, Grundlegung einer allgemeinen Translationstheorie. (Tübingen: Niemeyer. 1984), 13.

10 Strafprozessordnung - StPO vom Jahr 2019 (Stand: 09.10.2020. BGB1. IS. 1604), Zutritt am 27. Oktober $2020 \mathrm{http}: / /$ dejure.org/gesetze/StPO

11 Zakon o izmjenama $i$ dopunama Zakona o kaznenom postupku Republike Hrvatske vom 17.12.2019, Zutritt am 27. Oktober 2020, https://narodne-novine.nn.hr/clanci/ sluzbeni/2019_12_126_2530.html 


\section{DEUTSCHE METAPHORISCHE RECHTSTERMINI UND -KOLLOKATIONEN UND IHRE KROATISCHEN ENTSPRECHUNGEN}

Die gesammelten Belege werden ihrer lexikalischen Struktur nach eingeteilt. Jede Struktur wird danach nach folgenden drei Kriterien analysiert: a) Ausdrücke, deren kroatische Entsprechungen metaphorischen Charakters sind (wortwörtliche Übersetzungen), b) Ausdrücke, deren kroatische Entsprechungen metaphorischen Charakters sind, aber mit einer abweichenden lexikalischen Realisierung, und c) Ausdrücke, deren kroatische Entsprechungen nicht metaphorisch sind.

\subsection{Monolexikalische Ausdrücke in der deutschen StPO als metaphorische Fachtermini}

Im Korpus wurden zwölf Beispiele metaphorischen Charakters gefunden, die monolexikalische Rechtstermini sind.

a) Monolexikalische Ausdrücke metaphorischen Charakters, deren kroatische Entsprechungen wörtliche Übersetzungen metaphorischen Charakters sind: die Sache; der Streit; der Dritte; das Rechtsmittel; der Rechtsverkehr; die Geldwäsche, die Klageerhebung, die Beweiserhebung.

b) Die zweite Gruppe bilden die Einzelwörter, deren kroatische Entsprechungen Neubildungen sind, ohne ursprüngliche metaphorische Bedeutung: der Verletzte (oštećenik), der Vormund (skrbnik), die Verschleierung (prikrivanje), die Überwachung (nadzor).

c) In dieser Gruppe gibt es keine Entsprechungen im Kroatischen, die nicht metaphorisch sind.

\subsection{Metaphorische Kollokationen}

Unter Kollokationen versteht man feste Wortverbindungen, die nicht, oder nur schwach idiomatisiert sind (Burger, 1998). Sie werden auch als zwei oder mehr Wörter definiert, „die meistens in freien lexikalischen Verbindungen auftreten; das bedeutet dass sie gemeinsam eine Bedeutung tragen, während jedes Wort getrennt seine eigene Bedeutung trägt und in anderen lexikalischen Verbindungen auftreten kann. ${ }^{12}$

L'Homme und Bertrand haben die Kollokation folgenderweise definiert: „Collocation is a two-word term, semantic interdependence of its constituent parts representing its specific linguistic feature." ${ }^{\prime 3}$ Sie haben die Formen der Kollokationen in der englischen Sprache untersucht und folgende Strukturen von Kollokationen festgestellt: Adjektiv + Substantiv, Substantiv + Verb, Substantiv + Substantiv, Verb + Adverb. Dieselben Strukturen weisen auch die in zwei Korpora der deutschen und

12 Milica Gačić, Riječ do riječi. (Zagreb: Učiteljski fakultet Sveučilišta u Zagrebu i Profil, 2009), 280. Übersetzt vom Kroatischen ins Deutsche von der Autorin dieser Arbeit.

13 Marie-Claude L'Homme, und Claudine Bertrand, „Specialized Lexical Combinations: Should they be described as Collocations or in Terms of Selectional Restrictions?" in: Proceedings. Ninth Euralex International Congress (Stuttgart: Stuttgart University, 2000), 497-506. 
kroatischen Rechtssprache aufgefundenen Kollokationen auf. Die exzerpierten Belege werden nach diesen Strukturen eingeteilt, analysiert und diskutiert. Die Struktur Verb + Adverb wurde aus der Analyse ausgelassen, weil die Beispiele dieser Struktur keinen metaphorischen Charakter aufweisen. Als Grenzfälle der metaphorischen Ausdrücke werden hier auch die Syntagmen mit Funktionsverben analysiert.

\subsubsection{Metaphorische Kollokationen der Struktur Adjektiv + Substantiv}

Hier werden die Beispiele analysiert, in welchen das Adjektiv eine metaphorische Bedeutung in Bezug auf das Bezugssubstantiv trägt. Meistens besteht der metaphorische Charakter des Ausdrucks darin, dass abstrakte Eigenschaften den Bezeichnungen von Menschen, und die Eigenschaften von Personen den Bezeichnungen von Sachen bzw. von abstrakten Rechtsbegriffen zugefügt werden.

a) Kollokationen Adjektiv + Substantiv, deren kroatische Entsprechungen wortwörtliche Übersetzungen sind (mit metaphorischer Bedeutung)

- juristische Person

- natürliche Person

- entlastende Tatsache

- mildere Strafe,

- sachliche Zuständigkeit,

- auferlegte Kosten;

- materielles Recht, materielle Wahrheit;

- beglaubigte Abschriften.

Die kroatische Entsprechung der letzteren Kollokation ist etymologisch gesehen sehr interessant, weil das deutsche Grundsegment Glaub- durch das kroatische wörtliche Entsprechung vjera übersetzt und daraus ein Adjektiv abgeleitet wurde: ovjerene kopije.

b) Ausdrücke, deren kroatische Entsprechungen metaphorischen Charakters sind, aber mit einer abweichenden lexikalischen Realisierung

In folgenden Beispielen geht es um Kollokationen, in welchen das Adjektiv vom Funktionsverb abgeleitet ist. Der adjektivische Teil ist vom Funktionsverb treffen abgeleitet, dem im Kroatischen die Verben donijeti/dati entsprechen, dem Verb leisten (vom Funktionsverbgefüge Eid leisten), dem im Kroatischen das Funktionsverb dati entspricht (dati prisegu), und dem Verb erheben, dem im kroatischen eine abweichende lexikalische Form metaphorischen Charakters enspricht: iznijeti.

getroffene Maßnahme (abgeleitet vom FVG Maßnahmen treffen) - donesene mjere (donijeti mjere)

getroffene Anordnungen (abgeleitet vom FVG Anordnungen treffen) - dane naredbe (dati naredbe)

geleisteter Eid; (abgeleitet vom FVG Eid leisten) -

die erhobenen Beweise (abgeleitet vom FVG Beweise erheben).

C) kroatische Entsprechungen sind nicht metaphorisch

Der Ausdruck frische Tat (auffrischer Tat betreten) im Bereich der kroatischen Rechtssprache ist nicht metaphorisch: zateći koga na djelu, (uhvatiti koga in flagranti: 
zateći na samome djelu ${ }^{14}$.

\subsubsection{Metaphorische Kollokationen der Struktur: Substantiv + Substantiv}

Meistens handelt es sich um Nominalisierungen aus Verbalphrasen, in welchen der ursprüngliche verbale Teil ein Träger der metaphorischen Bedeutung ist. Kroatische Entsprechungen sind in der Regel auch metaphorisch, mit wörtlichen Übersetzungen. Im Korpus gibt es auch Beispiele, deren kroatische Entsprechungen eine andere semantische Metaphorik aufweisen als deutsche Originale, und zwei Beispiele, deren kroatische Entsprechungen nicht metaphorisch sind.

Ausdrücke, deren kroatische Entsprechungen metaphorischen Charakters sind (wortwörtliche Übersetzungen)

Einlegung des Rechtsmittels (von: Rechtsmittel einlegen - uložiti pravni lijek)

Eröffnung des Strafverfahrens (von: Strafverfahren eröffnen - otvoriti istražni postupak postupak)

Eröffnung des Hauptverfahrens (von: Hauptverfahren eröffnen-otvoriti glavni

Eintritt der Rechtskraft (von: in (Rechts)Kraft treten - stupiti na snagu)

Erfüllung der Aufgaben (von: Aufgaben erfüllen - ispunjavati zadaće)

Erhebung der Klage (von: Klage erheben - podići tužbu)

Auferlegung der Kosten (von: Kosten auferlegen - nametnuti troškove).

Diese metaphorischen Ausdrücke, die von deutschen Funktionsverbgefügen abgeleitet sind, wurden in die Kroatische wortwörtlich übernommen. Sie sind zum integralen Teil der kroatischen Rechtsphraseologie geworden, obwohl sie in der kroatischen Gemeinsprache in derselben übertragenen Bedeutung nicht gebräuchlich sind.

Als Konkurrenzformen kommen im Korpus auch zwei Zusammensetzungen statt Kollokationen vor: Klageerhebung, Beweiserhebung.

b) Ausdrücke, deren kroatische Entsprechungen metaphorischen Charakters sind, aber mit einer abweichenden lexikalischen Realisierung

In meisten Fällen handelt es sich um Kollokationen, in welchen der erste Teil von einem Funktionsverb abgeleitet ist. Die kroatischen Entsprechungen der Belege mit solchen Verben sind auch metaphorisch, aber mit einer abweichenden semantischen und lexikalischen Realisierung. Ein interessantes Beispiel ist die Kollokation Erhebung der Daten, die vom Ausdruck Daten erheben abgeleitet ist, wobei dem Verb erheben im Kroatischen das Verb iznositi (iznositi podatke) und nicht podići entspricht, wie im Fall der Kollokation Erhebung der Klage (podizanje tužbe), die wortwörtlich ins Kroatische übersetzt wurde.

Auch folgende Belege haben im Kroatischen eine abweichende semantische Realisierung metaphorischen Charakters: Ausübung der Begutachtung (von: Begutachtung ausüben -obavljati vještačenje), Erlass des Haftbefehls (von: Haftbefehl erlassen - izdati uhidbeni nalog).

c) Ausdrücke, deren kroatische Entsprechungen nicht metaphorisch sind

14 Hrvatska enciklopedija. Leksikografski zavod Miroslav Krleža, 2020, Zutritt am 28. Oktober 2020, http://www.enciklopedija.hr/Natuknica.aspx?ID= 
Nur zwei Belege werden ins Kroatische als nichtmetaphorische Ausdrücke übersetzt: Löschung der Mitteilung/ Löschung der Daten (abgeleitet von: Mitteilung/ Daten löschen - izbrisati poruku/ podatke).

\subsubsection{Metaphorische Kollokationen der Struktur: Substantiv + Verb}

Bei diesen Strukturen handelt es sich um die Verben, die durch ihren häufigen Gebrauch im Bereich des Rechts terminologisiert worden sind und deswegen als fachsprachliche (also: rechtssprachliche) Funktionsverben betrachtet werden können. Die Belege mit diesen Verben werden hier nach alphabetischer Ordnung der betreffenden terminologisierten Verben organisiert und dargestellt:

Ausdrücke, deren kroatische Entsprechungen metaphorischen Charakters sind (wortwörtliche Übersetzungen)

abgeben: Einwilligung abgeben, Äußerung abgeben, Aussage abgeben, Erklärung abgeben (kroatisch: dati pristanak/izjavu/ iskaz/ očitovanje)

auferlegen: Beschränkungen auferlegen, Pflichte auferlegen, Kosten auferlegen (kroatisch: nametati ograničenja/ obveze/ troškove)

berühren: Rechte berühren (kroatisch: dirati u, narušavati prava)

erbringen: Erkenntnisse erbringen, Ergebnisse erbringen (kroatisch: iznijeti spoznaje/ rezultate)

erfüllen: Prüfungsmerkmale erfüllen, Aufgaben erfüllen (kroatisch:ispunjavati obilježja ispita/ zadaće)

erschöpfen: Rechtsmittel erschöpfen, Maßregeln erschöpfen (kroatisch: iscrpjeti pravna sredstva/mjere)

gelangen: zur Kenntnis gelangen (kroatisch: doći do spoznaje)

Besonders bildungsproduktiv in der rechtsprachlichen Phraseologie sind folgende Funktionsverben:

eröffnen (otvoriti): Untersuchung eröffnen, Verfahren eröffnen, Strafverfahren eröffnen, Verhandlung eröffnen, Hauptverhandlung eröffnen

einlegen (uložiti): Berufung einlegen, Rehtsbehelf einlegen, Rechtsmittel einlegen, Beschwerde einlegen, Revision einlegen

erheben (podicii): Klage erheben, Beschwerde erheben, Einwendungen erheben, Beschuldigungen erheben

bestellen (postaviti): jemandem den Rechtsanwalt bestellen, anwaltlichen Beistand bestellen

In meisten Fällen kommen die Funktionsverben mit einem Objekt im Akkusativ vor. Im Korpus wurden auch einige Beispiele gefunden, die mit einem Subjekt im Nominativ stehen:

Rechte erwachsen; Rechte erlöschen; der Fristenlauf ruht; das Zeugnisverweigerungsrecht erstreckt sich auf...

Ausdrücke, deren kroatische Entsprechungen metaphorischen Charakters sind, aber mit einer abweichenden lexikalischen Realisierung

Typisches Beispiel für solche Verben ist das rechtsprachliche Funktionsverb erheben:

Tatbestand erheben; Daten erheben, Informationen erheben, Beweise erheben 
(iznijeti činjenično stanje/ podatke/ informacije/ dokaze).

Ausdrücke, deren kroatische Entsprechungen nicht metaphorisch sind

Im Korpus gibt es zwei Beispiele mit diesen Merkmalen: Rechte erwachsen, Rechte erlöschen (prava nastaju, prava prestaju).

\subsection{Metaphorische Präpositionalphrasen}

Unter metaphorischen Präpositionalphrasen werden hier die Phrasen aus einem Nomen und einer Präposition betrachtet. Da verbale Präpositionalphrasen vorwiegend um Funktionsverben gebildet sind, werden sie hier innerhalb der Syntagmen mit kroatischen Entsprechungen metaphorischen Charakters dargestellt und analysiert. Beispiele der nominalen Präpositionalphrasen:

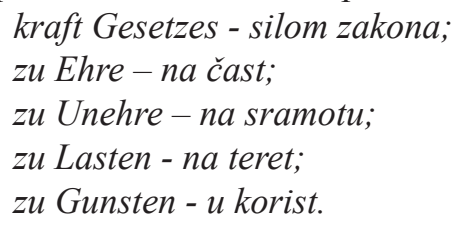

\subsection{Syntagmen mit Funktionsverben (Grenzfälle)}

Syntagmen mit Funktionsverben sind stark idiomatisierte Ausdrücke, in welchen die Funktionsverben ihre ursprüngliche Bedeutung verloren haben und durch die Häufigkeit des Gebrauchs geprägt sind. Deswegen sind sie nicht mehr als metaphorische Ausdrücke perzipiert.

Bei diesen Ausdrücken ist der niedrigste Grad der Überlappungen mit kroatischen Ausdrücken zu erwarten.

Syntagmen mit Funktionsverben, deren kroatische Entsprechungen metaphorisch sind (wortwörtliche Übersetzungen)

bringen: zu Akten bringen (unijeti u spise)

finden: Anwendung finden (nalaziti primjenu)

führen: Anklageschrift führen; Protokoll führen; Erforschung führen; Ermittlungen führen; Aufsicht führen; Strafverfahren führen; die Akten führen (voditi)

kommen: zur Kenntnis kommen, zur Entscheidung kommen (doći do)

geben: Auftrag geben, Einwilligung geben, Erklärung abgeben, Äußerung abgeben (dati)

haben: Bedeutung haben, Sitz haben, genügende Vorstellung haben (imati)

legen: zur Last legen - stavljati na teret

liegen: zur Last liegen - biti na teretu

nehmen: in Betracht nehmen - uzeti u obzir; in Schutz nehmen - uzeti u zaštitu; in Anspruch nehmen - uzeti u razmatranje

setzen: außer Kraft setzen - staviti izvan snage; in Kraft setzen - staviti na snagu; in Umlauf setzen - staviti u opticaj; in Kenntnis setzen - staviti/dati na znanje; in Verbindung setzen - staviti $u$ vezu; in Zweifel setzen - staviti u sumnju (auch das Vollverb: posumnjati - zweifeln); außer Zweifel setzen - staviti izvan sumnje 
treten: in Kraft treten - stupiti na snagu; in Verkehr treten (stupiti/ući u promet) ziehen: Schlüsse ziehen - izvući zaključke

b) Syntagmen mit Funktionsverben, deren kroatische Entsprechungen FV mit abweichenden lexikalischen und semantischen Realisierungen als im deutschen Ausdruck enthalten

machen: Anzeige machen, Mitteilung machen (dati-dati oglas/priopćenje)

leisten: Eid leisten (dati prisegu), Hilfe leisten (pružiti pomoć); Folge leisten (snositi posljedice). Das Verb leisten hat in kroatischen Entsprechungen drei verschiedene Realisationen: dati (wortwörtlich: geben), pružiti (wortwörtlich: leisten); snositi (wortwörtlich: tragen).

stehen: im Verhältnis stehen, in Frage stehen, in Verwendung stehen, in Widerspruch stehen (kroatische Entsprechung des FV stehen ist in diesen Ausdrücken das Hilfsverb sein = biti)

treffen: Vorbereitungen treffen, Entscheidung treffen, Beschluss treffen. Im Kroatischen erscheinen zwei lexikalische Formen als Entsprechungen des Verbs treffen: vršiti und donijeti (vršiti pripreme; donijeti odluku, donijeti rješenje).

ziehen: in Betracht ziehen (kroatische Entsprechung enthält das Funktionsverb uzeti (wörtlich: nehmen)

führen: obwohl dieses Funktionsverb in den Syntagmen erscheint, die wortwörtlich in kroatische Rechtssprache übernommen wurden, erscheint in einigen kroatischen Entsprechungen auch das Funktionsverb: nositi (bringen) und seine terminologisierte Version iznositi (erbringen): Staatszugehörigkeitszeichen führen, Beweis führen.

Vom Standpunt der Lexik und Semantik aus sind auch die Beispiele von verbalen Präfixbildungen höchst interessant, in welchen die Funktionsverben durch Zufügung eines Präfixes terminologisiert und zu juristischen Fachausdrücken geworden sind. Zahlreich sind solche Beispiele mit dem Funktionsverb bringen:

bringen - zu Akten bringen; zum Ausdruck bringen; jemandem einen Nachteil bringen (kroatische Entsprechungen enthalten drei verschiedene Verben: unijeti $\mathrm{u}$ spise, dovesti do izražaja, nositi nedostatke);

anbringen: Anlehnungsgesuch anbringen, Antrag anbringen, Anzeige anbringen, Revisionsanträge anbringen (hier ist krotische Entsprechung in allen Fällen ein einziges Verb: podnijeti zahtjev za potporu, podnijeti nalog, podnijeti prijavu, podnijeti/ podnositi zahtjeve za reviziju);

erbringen: Einwendungen gegen die Eröffnung des Hauptverfahrens erbringen (podnijeti prigovor), Post-oder Telekommunikationsdienste erbringen (vršiti poštanske i telekomunikacijske usluge), eine bestimmte Leistung erbringen (vršitil obavljati određene radnje); gemeinnützige Leistungen erbringen (vršiti radnje u vlastitu korist) - in kroatischen Entsprechungen erscheinen hier zwei Verben: podnijeti und vršiti;

vorbringen: Ablehnungsgründe vorbringen (iznijeti razloge odbijanja), Beanstandungen vorbringen, Beschwerde vorbringen, Einwendung vorbringen, (podnijeti pritužbu/žalbu/prigovor) - in diesem Fall erscheinen im Kroatischen auch zwei verschiedene Verben metaphorischen Charakters.

c) metaphorische Syntagmen mit Funktionsverben, deren kroatische 
Entsprechungen nicht metaphorisch sind

Bedenken finden - dvojiti, premišljati se

Beschränkung erfahren - biti ograničen

in Beschlag nehmen - zaplijeniti

in Verwahrung nehmen - čuvati

in Erfahrung bringen - spoznati.

Interessanterweise sind kroatische Entsprechungen dieser Belege monolexikalische Ausdrücke, die aus dem substantivischen Teil der Kollokation abgeleitet sind, wobei das deutsche Funktionsverb seine Bedeutung völlig verloren hat.

\section{METAPHORISCHE AUSDRÜCKE IM KROATISCHEN KORPUS}

Da die Texte der deutschen und der kroatischen Strafprozessordnung dem Inhalt und dem Umfang nach nicht identisch sind (das kroatische Gesetz ist noch umfangreicher als das deutsche) und keine kontrastive Analyse der metaphorischen Ausdrücke möglich ist, wird hier die Analyse der metaphorischen Ausdrücke im kroatischen Gesetz zur Änderung der Strafprozessordnung vom 17.12.2019 durchgeführt. Der Zweck dieser Analyse ist es, die Befunde der Analyse von Belegen aus dem deutschen Korpus und ihrer kroatischen Entsprechungen zu bestätigen. Die aus dem kroatischen Korpus exzerpierten Belege werden nach denselben lexikalischen Mustern wie die deutschen Belege eingeordnet und analysiert: 1) Monolexikalische metaphorische Ausdrücke, 2) Metaphorische Kollokationen der Struktur Adjektiv + Substantiv, 3) Metaphorische Kollokationen der Struktur Substantiv + Substantiv (Genitivattribut), 4) Metaphorische Kollokationen der Struktur Substantiv + Verb, 5) Präpositionalphrasen, 6) Syntagmen mit Funktionsverben als Grenzfälle.

\subsection{Monolexikalische metaphorische Ausdrücke}

Im Korpus des kroatischen Gesetzes werden fünf monolexikalische Ausdrücke metaphorischen Charakters gefunden: tijelo (der Körper), tijek (der Lauf/ Verlauf), teret (die Last), mjera (die Maßnahme), pravomoćnost (die Rechtskraft).

\subsection{Metaphorische Kollokationen Adjektiv + Substantiv}

Im Korpus sind neun Belege dieser Struktur gefunden. Ihre deutschen Entsprechungen sind auch metaphorische Ausdrücke derselben lexikalischen Struktur und derselben Bedeutung.

nadležno tijelo (zuständige Stelle/ zuständiges Organ)

vanjski poslovi (auswärtige Angelegenheiten),

teža kazna zatvora (schwerere Freiheitsstrafe),

pravno odlučne činjenice (rechtlich schlaggebende Tatsachen),

podneseni zahtjev (der gestellte Antrag),

postavljeni branitelj (der bestellte Verteidiger),

izvedeni dokazi (geführte Beweise) 
Dank dem deutschen Wortbildungssystem, in welchem die Komposita als häufigste Wortbildungsform der Substantive vorkommen, sind einige kroatische Ausdrücke dieser Struktur ins Deutsche als Komposita übersetzbar: pravna pomoć $=$ Rechtbehelf, kazneni progon = Strafverfolgung.

\subsection{Metaphorische Kollokationen Substantiv + Substantiv (Genitivattribut)}

Zwölf (12) Belege im kroatischen Korpus weisen diese Struktur auf. Eine Mehrheit davon wird ins Deutsche als Kompositum übersetzt: teret dokaza (Beweislast); mjera opreza (Vorsichtsmaßnahmen); predmet spora (Streitgegenstand), donošenje odluke (Entscheidungstreffen/ Entscheidungsfindung), podnošenje zahtjeva (Antragstellung), podizanje optužnice (Anklageerhebung); snošenje troškova (Kostentragen); izdvajanje dokaza (Beweisaufnahme); izvođenje dokaza (Beweisführung). In anderen Beispielen sind deutsche Entsprechungen derselben Struktur wie die kroatischen Belege: tijek postupka (Verlauf des Verfahrens), težina predmeta spora (die Schwere des Streitgegenstandes). Deutsche Entsprechungen der Kollokationen dieser Struktur sind auch metaphorisch.

\subsection{Präpositionalphrasen}

Obwohl im Korpus zahlreiche Beispiele der Präpositionalphrasen erscheinen, ist die Anzahl der metaphorischen Präpositionalphrasen relativ klein: na teret proračunskih sredstava (zur Last der Haushaltsgelder); stupanje na snagu (Inkrafttreten), zakonski propisi na snazi (geltende Rechtsvorschriften). Die letztere Präpositionalphrase „zakonski propisi na snazi“ ist im kroatischen aus dem Ausdruck stupiti na snagu (= in Kraft treten) abgeleitet. Diese metaphorischen Ausdrücke sind wörtliche Übersetzungen aus dem Deutschen, nur haben einige von ihnen eine andere lexikalische Form, wie z.B. eine Wortgruppe als Entsprechung der deutschen Zusammenbildung Inkrafttreten.

\subsection{Metaphorische Kollokationen der Struktur Verb + Substantiv}

$\mathrm{Zu}$ dieser Gruppe gehören die Beispiele, in welchen die Vollverben auf Grund des deutschen Originals terminologisiert worden sind und feste lexikalische Beziehungen in kroatischer Rechtssprache gebildet haben. Solche Strukturen kommen in zwei Formen vor: Verb + Akkusativobjekt und Verb mit dem Subjekt im Nominativ.

postaviti branitelja (den Verteidiger bestellen), podići tužbu (Klage erheben), poduzeti radnje (Handlungen vornehmen); zastara teče (Verjährung läuft), rokovi istječu (Fristen erlöschen).

Kroatische Ausdrücke und ihre deutschen Entsprechungen sind metaphorisch.

\subsection{Syntagmen mit Funktionsverben als Grenzfälle}

Syntagmen mit Funktionsverben sind stark idiomatisierte Ausdrücke, und als solche in der Allgemeinsprache und vielen Fachsprachen nicht mehr als metaphorische 
Ausdrücke perzipiert. Da die Funktionsverben ihre ursprüngliche Bedeutung verloren haben, können die Syntagmen mit Funktionsverben als Grenzfälle der metaphorischen Ausdrücke im Bereich des Rechts betrachtet werden. Die im kroatischen Korpus gesammelten Beispiele dieser Struktur werden hier nach dem Funktionsverb organisiert und dargestellt:

voditi (führen): voditi postupak (das Verfahren führen),

provoditi (durchführen): provoditi izvide, provoditi (kazneni) postupak (Ermittlungen durchführen; Strafverfahren durchführen)

dati (geben/ abgeben): dati suglasnost (Zustimmung zu etwas (ab)geben)

iznijeti (erbringen/anbringen/vorbringen): iznijeti prijedloge (Vorschläge erbringen/ anbringen/ vorbringen),

donijeti (erlassen, beschließen, erteilen, fällen, treffen): donijeti pravilnik (eine Verordnung erlassen/ beschließen), donijeti nalog (einen Auftrag erteilen), donijeti presudu (Urteil fällen), donijeti odluku (Entscheidung treffen).

Die Analyse der gesammelten Beispiele weist darauf hin, dass im deutschen Korpus die Anzahl der Funktionsverben größer ist als in der kroatischen Sprache. Einem kroatischen Funktionsverb entsprechen mehrere Funktionsverben in verschiedenen Gefügen im Deutschen. So entsprechen z.B. dem Verb donijeti (wortwörtlich: bringen) mehrere Funktionsverben im Deutschen: treffen, erlassen, beschließen, verabschieden, fällen: Maßnahmen treffen - donijeti mjere; Gesetze erlassen - donijeti zakon; Verordnung beschließen - donijeti uredbu; Verfassung verabschieden - donijeti ustav; Urteil fällen - donijeti presudu).

Besonders interessant sind Beispiele der Syntagmen mit Funktionsverben, die wortwörtlich aus dem Deutschen übernommen sind und einem kroatischen Muttersprachler als Laien im Bereich des Rechts als ungewöhnliche oder unlogische Ausdrücke vorkommen können: stavljati prijedloge (Vorschläge stellen), izvesti dokaze (Beweise führen), staviti na snagu (in Kraft setzen). Alle metaphorischen Syntagmen mit Funktionsverben in der kroatischen Rechtssprache haben auch im Deutschen ihre Äquivalenten des metaphorischen Charakters, wie auch andere Belege im kroatischen Korpus. Das bestätigt die Tatsache, dass metaphorische Ausdrücke des kroatischen Strafprozessrechts wortwörtlich aus der deutschen Rechtsterminologie übernommen sind.

\section{SCHLUSSFOLGERUNG}

Wie es im theoretischen Teil dieser Arbeit hervorgehoben wurde, ist der Einfluss des deutschen und des österreichischen Rechts auf die Gestaltung der kroatischen Rechtsregeln durch die Geschichte unbestritten. Selbstverständlich gründet sich auch die kroatische Rechtsterminologie auf die deutsche Rechtssprache. Dem viersprachigen Wörterbuch „Juridisch-politische Terminologie für die slawische Sprachen Österreichs" aus dem Jahr 1850 verdanken wir eine große Anzahl von Rechtstermini und Phrasen, die aus dem Deutschen ins Kroatische übersetzt sind. In Einklang mit den puristischen Bestrebungen zur Zeit der Nationalbewegungen in Europa Mitte des 19. Jh. wurden auch viele neue Rechtstermini gebildet. Einige 
Fachtermini wurden aber aus dem Deutschen ins Kroatische wortwörtlich übersetzt. Da metaphorische Ausdrücke und Kollokationen kulturbedingt und oft kaum übersetzbar sind, war das Anliegen dieser Arbeit, zu überprüfen, ob und in welchem Maße die metaphorischen Ausdrücke im Bereich der deutschen und der kroatischen Rechtssprache übereinstimmen. Eine beträchtliche Anzahl der semantischen Überlappungen und wortwörtlichen Übersetzungen solcher Ausdrücke sollte einen intensiven Einfluss der deutschen Rechtsterminologie und -phraseologie auf die kroatischen beweisen. $\mathrm{Zu}$ diesem Zweck wurden die qualitative und quantitative Analyse der aus dem Korpus exzerpierten Beispiele und ihrer kroatischen Äquivalenten durchgeführt. Metaphorische Ausdrücke der deutschen Rechtssprache wurden dem Text der deutschen Strafprozessordnung vom 15.11.2019, Stand: 01.09.2020 (BGB1. I S. 1604) und des kroatischen Gesetzes zu Änderungen der StPO der Republik Kroatien vom 17.12.2019 als Korpus der Untersuchung exzerpiert. Die in beiden Korpora gesammelten Belege wurden in folgenden Gruppen analysiert: 1) monolexikalische metaphorische Ausdrücke, 2) metaphorische Kollokationen der Struktur Adjektiv + Substantiv, 3) metaphorische Kollokationen der Struktur Substantiv + Substantiv (Genitivattribut), 4) metaphorische Kollokationen der Struktur Substantiv + Verb, 5) Präpositionalphrasen, 6) Syntagmen mit Funktionsverben als Grenzfälle. In jeder Gruppe wurden im deutschen Korpus die Belege nach dem metaphorischen Charakter ihrer kroatischen Entsprechungen in drei Untergruppen eingeteilt: a) Ausdrücke, deren kroatische Entsprechungen metaphorischen Charakters sind (wortwörtliche Übersetzungen), b) Ausdrücke, deren kroatische Entsprechungen metaphorischen Charakters sind, aber mit einer abweichenden lexikalischen Realisierung, und c) kroatische Entsprechungen, die nicht metaphorisch sind. Im deutschen Korpus wurden insgesamt 154 metaphorische Ausdrücke untersucht. Kroatische Entsprechungen von nur 13 dieser Belege sind nicht metaphorisch, während 95 Belege wortwörtliche metaphorische Übersetzungen sind. Entsprechungen von 41 Belegen sind auch metaphorischen Charakters, aber mit einer abweichenden lexikalischen und semantischen Realisierung in Bezug auf den deutschen Ausdruck. Das bedeutet, dass in 136 kroatischen Entsprechungen der metaphorische Charakter erhalten geblieben ist, was 88,31\% aller Belege bildet. Das beweist einen starken Einfluss der deutschen Rechtsterminologie auf die kroatische Terminologie des Strafprozessrechts trotzt kulturellen Unterschieden. Die Untersuchungsergebnisse der aus dem kroatischen Korpus exzerpierten Belegen bestätigen diesen Schluss: alle Beispiele ohne Ausnahme sind wortwörtliche metaphorische Übersetzungen von deutschen Rechtstermini. Die einzige lexikalisierte Ausnahme bildet der Ausdruck ,rokovi istječu“ (Fristen erlöschen).

Die Hypothese über einen beträchtlichen Einfluss der deutschen Rechtstermini auf kroatische Rechtsterminologie wurde dadurch bestätigt. Es ist interessant, dass deutsche Sprache einen stärkeren Einfluss im Bereich der Fachsprache Recht (hier im Bereich des Strafprozessrechts) ausgeübt hat als in der Allgemeinsprache. In der Rechtssprache sind nämlich 88,31\% von metaphorischen Ausdrücken in die kroatische Sprache des Rechts übernommen, während in der Alltagssprache (unter 98 von Buscha gesammelten Sprichwörtern) dieser Prozentsatz nur 28,5\% der deutschen 
Sprichwörter beträgt, die in derselben oder ähnlichen lexikalischen Form auch in der kroatischen Kultur bestehen (27 von insgesamt 98 Sprichwörtern).

Bei dieser Schlussfolgerung muss man doch auf die Begrenztheit dieser Untersuchung hinweisen, weil keine tiefere etymologische Analyse der Herkunft einzelner Ausdrücke gemacht wurde. Es ist klar, einerseits, dass einige deutsche Rechtstermini und Syntagmen aus dem Latein stammen, und andererseits, dass auch unter den Sprichwörtern der Alltagssprache sowohl die Einflüsse von lateinischen Sprüchen als auch Einflüsse anderer Kulturen anwesend sind. Der Leser muss auch dessen bewusst sein, dass die Untersuchung nur auf dem Gebiet des Strafprozessrechts durchgeführt wurde, und die Ergebnisse nicht unbedingt für alle andere Rechtsgebiete gelten sollten. Trotzdem ist es nicht übertrieben zu behaupten, dass die detailreiche Untersuchung einer beträchtlichen Anzahl von authentischen Beispielen zuverlässige Resultate ergeben hat, die für die deutsche und die kroatische Sprache des Straf(prozess) rechts als repräsentativ betrachtet werden können.

\section{LITERATURVERZEICHNIS}

1. Bösendorfer, Josip. Crtice iz slavonske povijesti. Osijek, Knjigo- i kamenotiskara Julija Feiffera 1910

2. Bukovčan, Dragica. „Integralni pristup frazeološkim i metaforičkim izrazima u području prava“. In: Lingvistički i pravni aspekti višejezičnosti, ur. Sočanac, Lelija, 243-276. Zagreb: Nakladni zavod Globus, 2013

3. Bukovčan, Dragica. „Wer sitzt hinter schwedischen Gardinen und wer spielt Klavier? Fachphraseologie und ihre kulturelle Relevanz". Jezikoslovlje, 16.1 (2015), 1-20.

4. Burger, Harald. Phraseologie. Eine Einführung am Beispiel des Deutschen. Berlin: Erich Schmidt Verlag, 1998

5. Buscha, Joachim. Deutsches Übungsbuch. Leipzig: VEB Verlag Enzyklopädie, 1979

6. Deutsche StPO von 2019, Stand: 9.10.2020 (BGB1. I S. 1604), http://dejure.org/gesetze/ StPO

7. Gačić, Milica. Riječ do riječi. Zagreb: Učiteljski fakultet Sveučilišta u Zagrebu i Profil, 2009

8. Günther, Lothar. Recht und Sprache. Wien, 1898

9. Hrvatska enciklopedija. Leksikografski zavod Miroslav Krleža, 2020 http://www. enciklopedija.hr/Natuknica.aspx?ID=

10. Husinec, Snježana. „Metafora u pravnom diskursu“. In: Zbornik radova s 24. međunarodnog znanstvenog skupa Hrvatskog društva za primijenjenu lingvistiku "Diskurs i dijalog: Teorije, metode i primjena", Hrsg. Vladimir Karabalić, Melita Aleksa Varga und Leonard Pon, 69-84. Osijek: Hrvatsko društvo za primijenjenu lingvistiku; Filozofski fakultet, 2011

11. Husinec, Snježana. Terminološki aspekti jezika hrvatske sudske prakse u razdoblju od 1848. do 1918. godine s posebnim osvrtom na njemački utjecaj. Unveröffentlichte Doktorarbeit. Zagreb: Filozofski fakultet Sveučilišta u Zagrebu, 2015

12. Kordić, Ljubica. "Metaphoric Use of Colour Denotations in the Language of Law". Studies in Logic, Grammar and Rhetoric 58/1 (2019): 101-124.

13. Kordić, Ljubica. „Metafora u njemačkom i hrvatskom pravnom idiomu“. Lingua Montenegrina, 6 (2010): 229-240.

14. Kövecses, Zoltan. Metaphor, A Practical Introduction. Oxford: Oxford University Press, 2002 
15. Lakoff, George, Mark Johnson. Metaphors we live by. Chicago: University of Chicago Press, 1980

16. Lakoff, George, Mark Turner. More than Cool Reason: A Field Guide to Poetic Metaphor. Chicago: University of Chicago Press, 1992

17. L'Homme, Marie-Claude und Claudine Bertrand. "Specialized Lexical Combinations: Should they be described as Collocations or in Terms of Selectional Restrictions?" In: Proceedings. Ninth Euralex International Congress, 497-506. Stuttgart: Stuttgart University, 2000

18. Mamić, Mile. Temelji hrvatskoga pravnog nazivlja. Zagreb: Hrvatska sveučilišna naklada, 1992

19. Mattila, Heikke. Comparative Legal Linguistics. Hampshire: Ashgate, 2006

20. Mažuran, Ive et al. Od turskog do suvremenog Osijeka. Zagreb: Šolska knjiga d.d. 1996

21. McKay, William R., Helen E. Charlton und Grant Barsoum, Legal English-how to understand and master the language of Law. Harlow, England: Longman-Pearson, 2011

22. Mihaljević, Milica und Ljiljana Šarić. „Metaforizacija kao terminološki postupak u engleskom i hrvatskom“. Suvremena lingvistika, 41/42 (1996), 437-449.

23. Reiss, Katarina und Hans Vermeer. Grundlegung einer allgemeinen Translationstheorie. Tübingen: Niemeyer, 1984

24. Zakon o izmjenama i dopunama Zakona o kaznenom postupku RH od 17.12.2019. (Gesetz zu Änderungen der StPO der Republik Kroatien vom 17.12.2019) https://narodne-novine. nn.hr/clanci/sluzbeni/2019_12_126_2530.html 
Prof. dr. sc. Ljubica Kordić*

Sažetak

\section{UTJECAJ NJEMAČKE PRAVNE TERMINOLOGIJE NA HRVATSKI JEZIK PRAVA NA PRIMJERU KAZNENOGA PROCESNOG PRAVA}

Iako se njemački i hrvatski pravni jezik temelje na različitim kulturama i pravnim sustavima, a sustavi tvorbe riječi njemačkog i hrvatskog jezika u velikoj se mjeri razlikuju, utjecaji njemačke pravne terminologije na hrvatski pravni jezik su i danas prepoznatljivi zbog povijesne utemeljenosti hrvatskog pravnog sustava u austrijskom pravu. Koliko su snažni utjecaji njemačkog jezika, najbolje se može vidjeti u prijevodima izraza metaforičnog i retoričkog karaktera, jer bi ti izrazi trebali biti svojstveni svakoj kulturi, a time i svakom jeziku ponaosob. Kako bi se dokazala hipoteza ovoga rada da je njemački pravni jezik snažno utjecao na hrvatski jezik prava, u ovoj se studiji istražuju hrvatski i njemački pravni pojmovi metaforičnog karaktera. Autor se služi metodom kvalitativne analize teksta, kvantitativnom i komparativnom metodom te analizira primjere kulturološki nijansiranih metaforičnih izraza, kolokacija i fraza na njemačkom i hrvatskom jeziku u području kaznenog procesnog prava. Korpus istraživanja čine tekst njemačkog Zakonika o kaznenom postupku od 15. studenoga 2019., status: 1. rujna 2020. i Zakona o izmjenama i dopunama Zakona o kaznenom postupku Republike Hrvatske od 17. prosinca 2019.

Ključne riječi: njemački jezik prava; hrvatski jezik prava; utjecaj; metaforički izrazi; pravne i povijesne veze.

* Dr. sc. Ljubica Kordić, izvanredna profesorica, Pravni fakultet Sveučilišta J. J. Strossmayer u Osijeku; kljubica@pravos.hr. ORCID: https://orcid.org/0000-0002-2900-7906.

Ovaj red je rezultat projekta u potpunosti financiranog od strane Jean Monnet Module Language i EU Law Excellence LEULEX br. 620231-EPP-1-2020-1-HR-EPPJMO-MODULE. Sadržaj ovog rada predstavlja isključivo mišljenja autorice i isključivo je njena odgovornost. Europska komisija ne prihvaća nikakvu odgovornost za korištenje informacija koje sadrži. 